\title{
Evidência de validade do teste de conhecimento tático processual para orientação esportiva - TCTP: OE
}

CDD. 20.ed. 152.3

796.011

http://dx.doi.org/10.1590/1807-55092015000200313

\author{
Pablo Juan GRECO* \\ Juan Carlos PEREZ MORALES* \\ Layla Maria Campos ABURACHID** \\ Schelyne Ribas da SILVA**
}

*Escola de Educação

Física, Fisioterapia e

Terapia Ocupacional, Universidade Federal de Minas Gerais.

**Faculdade de Educação Física, Universidade Federal de Mato Grosso.

\section{Resumo}

Este estudo objetivou investigar a evidência de validade de conteúdo, de construto e confiabilidade do teste de conhecimento tático processual para orientação esportiva (TCTP: OE) de crianças e jovens nos jogos esportivos coletivos de invasão (basquetebol, futsal e handebol). No processo de validade de conteúdo participaram como juizes 11 técnicos, sendo três de basquetebol, quatro de futsal e quatro de handebol. Nos procedimentos empíricos a amostra foi composta por um total de 570 participantes. A média de idade dos participantes do estudo foi de 10,32 $\pm 1,45$ anos. A validade de conteúdo foi determinada pelo cálculo do coeficiente de validade de conteúdo (CVC). Utilizou-se análise fatorial exploratória (AFE) para a validade de construto. 0 método utilizado foi 0 de componentes principais com rotação ortogonal Varimax e normalização Kaiser. A Confiabilidade do TCTP: $\mathrm{OE}$ foi estabelecida, por meio do método teste re-teste em dias diferentes. A técnica usada foi a correlação intraclasse (ICC). Em relação à validade de conteúdo o $\mathrm{CVC}$ calculado para clareza da linguagem $\left(\mathrm{CVC}_{t}=0,83\right)$, pertinência prática $\left(\mathrm{CVC}_{t}=0,91\right)$ e relevância teórica $\left(\mathrm{CVC}_{t}=0,95\right)$ foi satisfatório. A análise fatorial exploratória confirmou a estrutura do modelo final com dois fatores, denominados de ataque e defesa, explicando em todos os casos acima de 66\% da variância. Em relação à confiabilidade do instrumento o TCTP: OE apresentou valores satisfatórios e excelentes (ICC $\geq 0,4$ ). Conclui-se que o TCTP: OE viabiliza a avaliação do jogador seja com mão/ pé, o que determina uma avaliação condizente com os atuais preceitos da iniciação esportiva.

Palavras-chave: Desempenho tático; Tomada de decisão; Comportamento tático; Validação.

\section{Introdução}

$\mathrm{Na}$ investigação científica nos jogos esportivos coletivos (JEC) se coloca a necessidade do estudo e da formulação de procedimentos de diagnóstico para determinar o nível de rendimento tático de atletas e equipes, seja em uma competição ou durante o processo de treinamento nas fases de formação ou de alto rendimento. Entende-se paralelamente o valor pedagógico dos testes como importantes procedimentos avaliativos no processo de ensino-aprendizagem, e de treinamento. Sua aplicação delimita níveis de rendimento e consequentemente possibilita um planejamento direcionado adequadamente, por exemplo, na distribuição de conteúdos nas aulas ou sessôes a fim de equilibrar possíveis desvios, carências, bem como ser utilizado para a descoberta de talentos. Portanto, cresce a necessidade de se desenvolver instrumentos validos e confiáveis para analisar o nível de conhecimento tático (declarativo e processual) dos praticantes de JEC.

Estudos na área da Psicologia do Esporte direcionados a compreender os mecanismos e as interaçóes entre comportamento tático e os processos cognitivos (percepção, atenção, concentração, memória, tomada de decisão, solução de problemas, representações mentais, criatividade, entre outros aspectos) oferecem sustentação teórica importante na formulação das propostas pedagógicas e metodológicas de ensinoaprendizagem, nomeadamente do processo de treinamento tático, do treinamento técnico e das relaçóes deste com o desenvolvimento da criatividade ${ }^{1-15}$.

Assim, compreender os resultados dos métodos e processos de ensino-aprendizagem-treinamento, bem como conhecer as influências destes no desenvolvimento 
das capacidades táticas dos praticantes, são desafios para pesquisadores no sentido de elaborar procedimentos adequados para avaliar o nível de conhecimento tático (declarativo e processual) de atletas e praticantes de JEC nas diferentes formas de expressão do mesmo, isto é, esporte de lazer, esporte de prevenção da saúde, esporte escolar, esporte de reabilitaçâo e esporte de rendimento ${ }^{16}$.

A avaliação e análise do comportamento tático nos JEC demanda a realizaçáo de investigaçôes que revelem o caráter relacional e adaptativo das capacidades táticas com as outras capacidades implícitas no rendimento esportivo em situaçôes de jogo. Particularmente se avaliar o nível de conhecimento tático processual do praticante de JEC em situaçôes que se assemelhem as que este defronta na competição, permitiria identificar a interação das capacidades do rendimento à tomada de decisão, via realização do gesto técnico, visando solucionar adequadamente os diferentes problemas que defronta no contexto de uma situação de jogo seja no ataque ou na defesa.

Observam-se na literatura vários instrumentos para mensuraçáo do conhecimento tático processual nos JEC, por exemplo, o denominado FUT-SAT ${ }^{17}$, o procedimento de avaliaçáo desenvolvido por FRENCH e Thomas ${ }^{18}$, o Time Sports Assessment Performance $\left(\right.$ TSAP) ${ }^{19}$, o Game-test Situation (GTS) ${ }^{20-21}$, ou o Game Performance Assessment Instrument (GPAI) ${ }^{22}$. A avaliação do conhecimento tático processual proposta por tais instrumentos se centra na detecção desses princípios táticos durante a execução das açóes tático técnicas necessárias à situação de ataque e de defesa, no contexto do jogo formal ou do jogo reduzido. Isto é, a avaliação desconsidera as açóes específicas que executa o praticante em situação de ataque com bola e sem bola, assim como em situação de marcação ao jogador com bola e sem bola. A avaliação direta dessas açôes contribuiria para determinar de maneira direta o impacto do método de ensino-aprendizagem nos JEC.

$\mathrm{O}$ processo de desenvolvimento e validação desses instrumentos centrou-se no estabelecimento das evidências de validade de conteúdo, validade de construto e de confiabilidade, por meio da manifestação dos princípios táticos comuns aos JEC. A validade de um instrumento de testagem se define pelo grau em que todas as evidências confirmam a interpretação pretendida dos escores, conforme o objetivo para o qual foi desenvolvido ${ }^{23}$. A validação de um instrumento, isto é, o processo pelo qual são obtidas as evidências de validade, inicia-se pela afirmaçáo explícita do referencial conceitual e teórico do seu criador ${ }^{23}$.

As evidências de validade são consideradas como aspectos de validade de construto do instrumento desenvolvido, isto é, fontes de evidências de validade relacionada com o sentido ou interpretaçáo dos escores do teste ou instrumento e as inferências que podem ser elaboradas a partir da variável que está sendo mensurada ${ }^{23}$.

Entende-se construto como os traços, processos, conhecimentos ou características que se pretende identificar por meio de amostras específicas de comportamentos coletadas pelo instrumento proposto, isto é, aquilo que o criador do teste pretende medir ${ }^{22}$. Conforme a literatura especializada na área observa-se que os principais aspectos da validade de construto estáo relacionados ao conteúdo, padróes de convergência e divergência, assim como ao critério $^{23-24}$.

A confiabilidade do instrumento se apoia na consistência e precisáo dos resultados do processo de mensuraçáo, isto é, a qualidade dos escores deve apresentar um alto nível de consistência e se apresentar livre de erros de mensuração ${ }^{23}$. $\mathrm{Na}$ área da psicometria a confiabilidade dos escores se apresenta como condição necessária para o processo de validação do teste, porém não é suficiente. Isto é, entende-se a confiabilidade como um tipo de evidência mínima para obtenção de uma medida válida ${ }^{23}$.

Nesse contexto, objetivou-se investigar a evidência de valide de conteúdo, de construto e confiabilidade do teste de conhecimento tático processual para orientação esportiva (TCTP: OE) de crianças e jovens nos jogos esportivos coletivos de invasão.

\section{Método}

Esta pesquisa abordou o modelo para elaboração de instrumentos psicométricos proposto por PAsquali ${ }^{25}$.

Este estudo foi aprovado pelo Comitê de Ética em pesquisa da Universidade Federal de Minas Gerais sob o número CAAE - 0734.0.203.000-12. Todos os participantes, bem como os pais ou responsáveis preencheram o Termo de Consentimento Livre e Esclarecido.

No processo de validade de conteúdo do TCTP: OE participaram como juízes 11 técnicos, sendo três de basquetebol, quatro de futsal e quatro de handebol. Todos formados em educação física com titulação mínima de mestrado e com experiência 
mínima de 10 anos no processo de iniciação esportiva, especialização e alto nível de rendimento em cada uma das modalidades esportivas citadas.

Nos procedimentos empíricos a amostra foi composta por um total de 570 participantes, sendo que 321 realizaram o procedimento denominado de TCTP: OE1 com duração de três minutos e 570 realizaram o procedimento denominado de TCTP: OE2 com duração de quatro minutos. Ambos os procedimentos foram executados tanto com a mão quanto com o pé. A média de idade dos participantes do estudo foi de 10,32 $\pm 1,45$ anos. A idade mínima foi de oito anos e a máxima de 13 anos.

A construção do TCTP: OE requisitou a execução dos procedimentos teóricos, empíricos e analíticos conforme indicado na literatura ${ }^{25}$. Nos procedimentos teóricos considerou-se como sistema psicológico o conhecimento tático nos JEC. Sua propriedade está definida pelo conhecimento tático processual ou de procedimento que o praticante possui. $\mathrm{O}$ conhecimento tático processual nos JEC é definido como a realização de açóes motoras (denominadas, na área das ciências do esporte, de técnicas, isto é de gestos motores específicos de cada modalidade esportiva), que possibilitam ao jogador saber como e quando agir, selecionando o gesto técnico mais adequado para resolver os problemas da competição ${ }^{18,26-27}$.

Nesse contexto, entende-se que as açóes dos praticantes acontecem dentro de duas situaçóes ou dimensóes. A primeira situação ou dimensão está representada pelas açóes do jogador no ataque sem posse e com posse de bola, isto é, um dos jogadores da equipe no ataque está com a bola em suas máos e os demais colegas no ataque em atitude ofensiva, procuram se movimentar para que a ação do jogador com a bola seja realizada com sucesso e executar o passe. A segunda situação ou dimensão se manifesta por meio das açóes do jogador na defesa, na qual o conjunto de jogadores sem a bola procura recuperá-la e iniciar a troca de passes no intuito de manter a pose de bola.

OTCTP: OE foi construído para avaliar o conhecimento tático processual do praticante dos JEC em situaçóes de ataque e defesa. Para isso, foram propostos critérios de observação do jogador no ataque sem posse de bola (JSB) e com posse de bola (JCB) e do jogador na defesa marcando ao jogador sem posse de bola (MJSB) e com posse de bola (MJCB).

$\mathrm{Na}$ construção do TCTP: OE foram propostos inicialmente 18 itens para avaliar o conhecimento tático processual do praticante. A análise teórica desses itens foi realizada por meio da técnica para avaliação da validade de conteúdo proposta por
Hernández-Nieto ${ }^{28}$. Assim, foi determinada a validade de conteúdo da clareza de linguagem $(\mathrm{CL})$, da pertinência prática $(\mathrm{PP})$ e da relevância teórica (RT), por meio do cálculo do Coeficiente de Validade de Conteúdo para cada item do instrumento $\left(\mathrm{CVC}_{\mathrm{c}}\right)$ e para o instrumento como um todo $\left(\mathrm{CVC}_{\mathrm{t}}\right)$. Nesse processo, os 11 juízes avaliaram os itens propostos atribuindo nota utilizando uma escala tipo Likert de um (inadequado) até cinco pontos (muito adequado), em que avaliaram o nível de adequação dos itens do ponto de vista da CL, da PP e da RT. Hernández-Nieto ${ }^{28}$ recomenda que os itens do instrumento devam apresentar um valor mínimo de CVC igual a 0,8 . Com relação à CL, caso o item apresente valores inferiores a 0,8 , o autor preconiza que a linguagem seja reformulada para melhor entendimento da questáo pela populaçãoalvo. No que diz respeito à $\mathrm{PP}$, itens com valores de CVC inferiores a 0,8 devem ser descartados, pois náo são considerados pertinentes para a realidade da população-alvo. Em relação à RT, para este estudo os itens com valores inferiores a 0,8 foram reformulados conforme as sugestóes e observaçôes dos juízes.

$\mathrm{O}$ procedimento de campo proposto para avaliar o conhecimento tático processual de praticantes dos JEC entre os oito e os 14 anos de idade, consiste em uma situação de jogo reduzido de três contra três (3x3) sem finalização (ou seja, objetiva-se que joguem mantendo a posse da bola), para orientação sobre suas capacidades relacionadas aos jogos esportivos coletivos de invasão (basquetebol, futsal e handebol). O teste se apoia no instrumento proposto por Memmert e Roth ${ }^{20}$ e Memmert ${ }^{21}$ denominado de Game-test Situation (GTS), e se assemelha à proposta do Game Performance Assessment Instrument (GPAI) ${ }^{22}$. Diferencia-se dos mesmos pela sua facilidade de análise, considerando somente a presença ou ausência (frequência) de determinados parâmetros.

$\mathrm{O}$ protocolo para validação do procedimento de avaliação compreende a situação de jogo de 3x3 em um espaço de 9x9 metros, sendo duas as formas de aplicação do teste: o TCTP: OE1 e o TCTP: OE2. No TCTP: OE1 os três jogadores que atuam no ataque devem trocar a maior quantidade possível de passes durante três minutos usando as mãos, posteriormente jogam durante três minutos usando os pés. Os três jogadores que atuam na defesa só poderão interceptar os passes, porém são impedidos de tirar a bola das máos ou dos pés do jogador no ataque. Caso obtenham a bola, devem devolvê-la ao time em ataque, que reinicia o jogo do centro do quadrado. Após os três minutos de jogo, os participantes que 
estavam na função de ataque assumem a função de defensores e vice-versa. Inicia-se assim um novo jogo com a mesma duração e condiçóes do anterior.

No TCTP: OE2 é utilizada a mesma situaçáo de igualdade numérica no jogo $(3 \times 3)$ e o mesmo espaço usado no TCTP: OE1, porém o objetivo do jogo consiste em manter a posse de bola durante quatro minutos, por meio da troca de passes (uma aplicação com as máos e outra com os pés). Os três jogadores na defesa poderão recuperar a posse de bola, de acordo com a situação em que a troca de passes acontece, procurando a interceptação dos passes ou tirando a bola das mãos ou dos pés do atacante, porém sem retirar esta da posse do adversário, respeitando as regras do jogo de basquetebol, futsal e handebol. Se isto acontecer, os jogadores que estavam exercendo a função de defensores, rapidamente deverão assumir a funçáo de atacantes e iniciar a troca de passes para manter a posse de bola. Para incentiválos se solicita que computem a quantidade de passes realizados, cabendo à equipe adversária evitar a troca desses passes. Desta forma, o teste assemelha-se a um dos jogos frequentemente utilizados nas modalidades esportivas, denominado jogo dos 10 passes.

Todos os jogos de $3 \times 3$ foram filmados e posteriormente analisados por três avaliadores, formados em educação física com experiência prática no basquetebol, no futsal e no handebol. A avaliação do conhecimento

\section{Resultados}

No que se refere ao perfil da amostra, a porcentagem das instituiçóes em que os participantes do estudo desenvolvem suas práticas esportivas é de $51 \%$ nas escolinhas de formaçáo esportiva, 7,4\% nos projetos esportivos sociais e $41,6 \%$ em outro tipo de instituição (por exemplo, categoria de base em clube, escola, aula de educação física).

Em relação à participação nas aulas de educação física, $85,2 \%$ respondeu que participa das aulas de educação física e 14,8\% afirma que não. Dos sujeitos que participam das aulas de educação física, 85,2\% afirmaram que praticam esportes na aula de educação física e 14,8 afirmaram que não. No que se refere à participação em um processo de treinamento, 33,3\% afirmaram que participam ou treinam alguma modalidade esportiva, já os $66,7 \%$ restantes afirmaram que não participam ou treinam alguma modalidade esportiva em horário extraclasse. Das modalidades esportivas praticadas pelos participantes do estudo se confirmou que 5,8\% praticam basquetebol, 15,2\% tático processual seguiu os critérios de observação - itens propostos e validados por meio do cálculo do CVC, sendo necessária a realizaçáo do treinamento dos avaliadores, por meio da análise de duas cenas - jogos em companhia dos pesquisadores responsáveis. Dessa maneira, foi possível tirar as dúvidas que surgiram e alinhar o entendimento em relação aos critérios de observação.

Para avaliaçáo do conhecimento tático processual no TCTP: OE1 e TCTP: OE2 com a mão e com o pé se determinou o registro da frequência de aparecimento dos itens ou critérios de observação. Dessa maneira, o avaliador registrou se o comportamento foi realizado ou não e quantas vezes foi observado.

A validade de construto do TCTP: OE foi determinada, por meio da análise fatorial exploratória (AFE). O método utilizado foi o de componentes principais com rotação ortogonal Varimax e normalização Kaiser. Os dados foram analisados por meio do pacote estatístico SPSS ${ }^{\circledR} 16.0$ (Statistical Package for Social Science) for Windows ${ }^{\circledR}$.

A confiabilidade do TCTP: OE foi estabelecida, por meio do método teste re-teste em dias diferentes. O intervalo de tempo entre uma observação e a outra foi de sete dias. A técnica usada foi a correlação intraclasse (ICC), considerando no mínimo 10\% da amostra total. Para este estudo 154 participantes foram reavaliados, configurando $27 \%$ da amostra ${ }^{29}$.

futsal e 7,4\% voleibol. Nessa amostra 3,7\% pratica duas modalidades esportivas, $1,2 \%$ três modalidades esportivas e $66,7 \%$ nenhuma modalidade esportiva.

Em relação ao nível de experiência dos participantes do estudo em cada uma das modalidades esportivas praticadas, confirmou-se que $26,7 \%$ tem menos de uma ano de experiência, 9,1\% um ano de experiência, $14 \%$ dois anos de experiência, $7 \%$ três anos de experiência, $1,6 \%$ cinco anos de experiência e $2,5 \%$ com mais de cinco anos de experiência. $39,1 \%$ afirma que não possui experiência nenhuma na modalidade.

Do ponto de vista da validade de conteúdo do TCTP: OE, a TABELA 1 apresenta o $\mathrm{CVC}_{\mathrm{t}}$ total para CL, PP e RT do instrumento, a partir das notas atribuídas pelos peritos em cada modalidade esportiva (basquetebol, futsal e handebol). Os itens que foram desconsiderados por não terem alcançado o ponto de corte recomendado no quesito PP, também estão relacionados na TABELA 1. 
TABELA 1 - Resultados do cálculo do $\mathrm{CVC}_{\mathrm{t}}$ para clareza de linguagem, pertinência prática e relevância teórica do TCTP: OE.

\begin{tabular}{lcccc}
\hline Critério de validade & $\begin{array}{c}\text { Basquetebol } \\
\text { CVCtotal }\end{array}$ & $\begin{array}{c}\text { Futsal } \\
\text { CVCtotal }\end{array}$ & $\begin{array}{c}\text { Handebol } \\
\text { CVCtotal }\end{array}$ & Itens desconsiderados \\
\hline Clareza de linguagem & 0,88 & 0,82 & 0,8 & Item 3: 0,75 \\
Pertinência prática & 0,92 & & & Item 4: 0,75 \\
& & 0,87 & 0,94 & Item 5: 0,70 \\
Relevância teórica & 0,98 & & & Item 8: 0,72 \\
\hline
\end{tabular}

O cálculo do CVC determinou que dos 18 itens propostos, o item 3 (afasta-se do portador da bola criando linhas de passe sem prejudicar sua progressão), o item 4 (aproxima-se do portador da bola criando linhas de passe sem prejudicar sua progressão), o item 5 (Finta e avança/dribla ou passa a bola) e o item 8 (passa ao colega sem marcação e desloca em sua direção para passar pelas costas e receber), deveriam ser desconsiderados por não terem alcançado um CVC $\geq 0,80$ no quesito pertinência prática (PP), isto é, os juízes avaliaram esses itens como açóes tático-técnicas que não representam comportamentos típicos das modalidades esportivas do basquetebol, futsal e handebol na situação de igualdade númerica de $3 \times 3$ proposta neste estudo para avaliar o conhecimento tático processual. Em relação a clareza da linguagem (CL), os itens 1 a 11 e 17 foram reformulados conforme as ponderaçóes dos juízes, por terem valores do $\mathrm{CVC}$ abaixo do ponto de corte $(\mathrm{CVC} \geq 0,80)$ e reavaliados. Finalmente, todos os juízes concordaram em afirmar que o item 15 (apoia aos colegas na defesa criando superioridade numérica ou dupla marcação) deveria ser reformulado e ser parte da dimensão $\mathrm{MJCB}$ e não da dimensão MJSB como foi proposto inicialmente pelos pesquisadores.

$\mathrm{O}$ seguinte passo foi realizar o teste piloto para verificar se os 14 itens que alcançaram valores do CVC acima do ponto de corte recomendado nos quesitos avaliados (CL, PP e RT) eram comportamentos observáveis e típicos em uma situação de 3×3 em campo reduzido sem finalização. Após esse procedimento constatou-se que na dimensão JSB dois comportamentos deviam estar presentes no instrumento além dos dois itens já presentes e aprovados pelos juízes.

Nesse contexto, foram propostos mais dois itens para a dimensão JSB e encaminhados para avaliação dos juízes. A TABELA 2 apresenta a versão final do TCTP: OE após o cálculo do CVC com quatro itens ou critérios de observação para cada situação avaliada. Após esses novos procedimentos o TCTP: OE obteve valores satisfatórios para CL $\left(\mathrm{CVC}_{\mathrm{t}}=0,83\right)$, para PP $\left(\mathrm{CVC}_{\mathrm{t}}=0,91\right)$ e para $\mathrm{RT}\left(\mathrm{CVC}_{\mathrm{t}}=0,95\right)$.

TABELA 2 - Versão final do TCTP:OE após o cálculo do CVC.

\section{Teste de conhecimento tático processual: orientaçáo esportiva (TCTP: OE)}

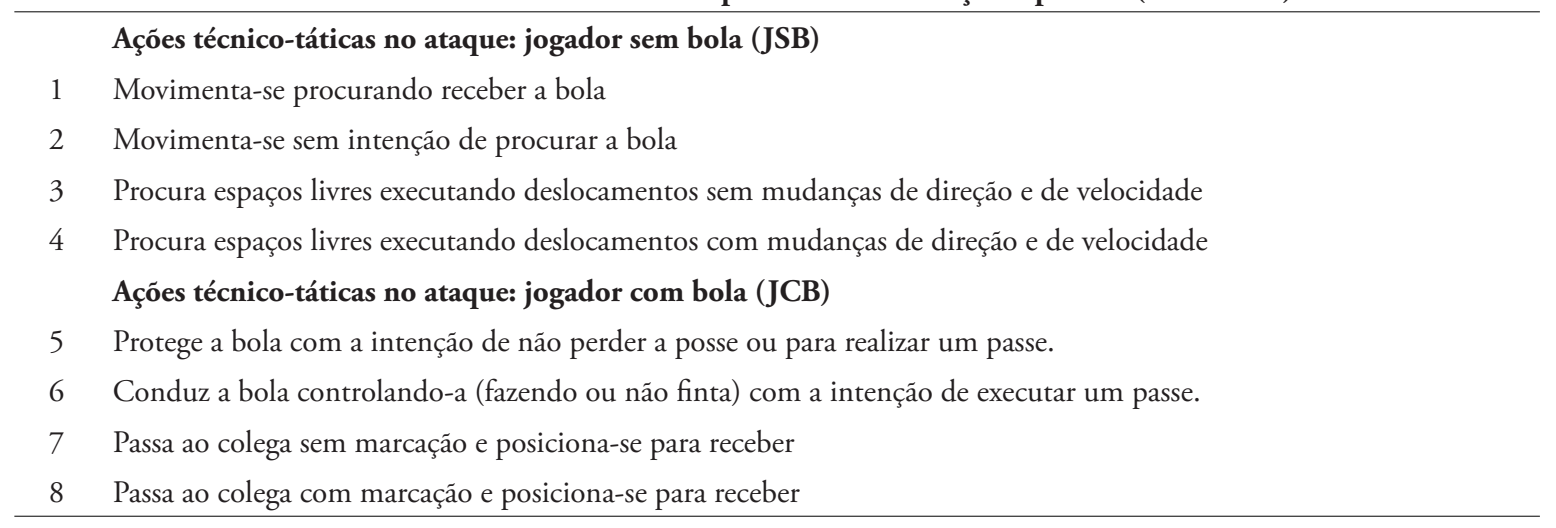

Continua 
TABELA 2 - Versão final do TCTP:OE após o cálculo do CVC (continuação).

\begin{tabular}{cl}
\hline & \multicolumn{1}{c}{ Teste de conhecimento tático processual: orientaçáo esportiva (TCTP: OE) } \\
\hline & Açóes técnico-táticas na defesa: marcaçáo ao jogador sem bola (MJSB) \\
9 & Acompanha os deslocamentos do adversário que tenta se desmarcar \\
10 & Desloca-se para interceptar ou antecipar o passe \\
11 & Apoia aos colegas na defesa (cobertura) quando são superados pelo adversário \\
12 & Apoia ao colega na defesa quando o jogador com bola tem dificuldade para dominá-la \\
& Açóes técnico-táticas na defesa: marcaçáo ao jogador com bola (MJCB) \\
13 & Marca à distância mantendo o controle visual do jogador com bola \\
14 & Pressiona ao adversário e acompanha seus deslocamentos \\
15 & Pressiona ao adversário tentando tirar a bola ou induzindo ao erro \\
16 & Pressiona ao adversário levando-o para os cantos do campo de jogo \\
\hline
\end{tabular}

Os resultados da AFE do TCTP: OE serão apresentados para cada tipo de procedimento (TCTP: OE1 e TCTP: OE2) tanto com a mão quanto com o pé.

A verificação da adequação amostral para o emprego da técnica da análise fatorial foi confirmada por meio do índice KMO (Kaiser-Meyer-Olkin). Este índice varia de 0 a 1 . Valores menores que 0,5 indicam que não se deve utilizar a análise fatorial, sendo necessárias medidas de correção nos dados amostrais por meio de exclusão de variáveis ou inclusão de novas variávei ${ }^{25,30}$.

Além disso, a prova de esfericidade de Bartlett também foi utilizada para verificar se existem correlaçôes significativas $(\mathrm{p}=0,0001)$ entre as variáveis e se o modelo fatorial era pertinente.

A seguir, realizou-se a análise das comunalidades, dos autovalores e dos percentuais de variância explicada para cada componente, assim como o percentual de variância total explicada. As comunalidades representam a proporção (quantidade) da variância de cada variável que pode ser explicada pelo modelo fatorial obtido. A partir das comunalidades foi possivel analisar se os fatores obtidos eram suficientes para explicar todas e cada uma das variáveis incluídas na análise $e^{25,30}$. A análise dos autovalores constitui um dos critérios para decidir sobre o número de fatores que deveriam ser extraídos. Os fatores que alcançaram autovalores igual ou acima de 1 foram mantidos.

A TABELA 3 apresenta os valores das comunalidades e carga fatorial dos cinco itens que carregaram satisfatoriamente em um dos dois fatores definidos pelo critério dos autovalores ou regra de Kaiser (componente $1=2,283$ e 45,664\% de variância explicada e componente $2=1,455$ e $29,101 \%$ de variância explicada), para o TCTP: OE 1 executado com a mão.

TABELA 3 - Comunalidade e carga fatorial dos cinco itens definidos na solução final rotada (VARIMAX) para o TCTP:OE 1 realizado com a mão.

\begin{tabular}{llccc}
\hline & Itens selecionados & Comunalidade & \multicolumn{2}{c}{ Carga fatorial } \\
& & & Fator 1 & Fator 2 \\
\hline 1 & Movimenta-se procurando receber a bola (JSB). & 0,725 & 0,020 & 0,851 \\
8 & Passa ao colega com marcaçáo e posiciona-se para receber (JCB). & 0,730 & $-0,004$ & 0,854 \\
11 & $\begin{array}{l}\text { Apoia aos colegas na defesa (cobertura) quando são superados pelo } \\
\text { adversário (MJSB). }\end{array}$ & 0,758 & 0,870 & $-0,024$ \\
12 & $\begin{array}{l}\text { Apoia ao colega na defesa quando o jogador com bola tem } \\
\text { dificuldade para dominá-la (MJSB). }\end{array}$ & 0,725 & 0,851 & 0,019 \\
16 & Pressiona ao adversário levando-o para os cantos do campo de jogo (MJCB). & 0,800 & 0,894 & 0,030 \\
\hline
\end{tabular}

Na TABELA 3 observa-se que os itens 1 e 8 , que representam situaçóes de ataque sem bola e com bola, apresentam carga fatorial satisfatória no fator 2. Os itens 11, 12 e 16, relacionados a situaçôes de defesa marcando ao jogador no ataque sem bola e com bola, carregam satisfatoriamente no fator 1. Nesse contexto, os pesquisadores optaram por denominar o fator 1 de defesa e o fator 2 de ataque. A porcentagem total de variância explicada pelo modelo final alcançado foi de $74,764 \%$. 
O valor do KMO calculado com os cinco itens que apresentaram cargas fatoriais satisfatórias no modelo final resultante foi de 0,670 , indicando que a técnica da análise fatorial pode ser utilizada para a amostra em questão. A prova de esfericidade de Bartlett demonstrou que existem correlações significativas (Qui-quadrado $=433,246 ; \mathrm{df}=10 ; \mathrm{p}=0,0001$ ) entre as variáveis e o modelo fatorial é pertinente.

No caso do TCTP: OE 1 realizado com o pé, não foi possível alcançar um modelo final satisfatório. $\mathrm{O}$ critério dos autovalores definiu dois componentes ou fatores (componente $1=2,096$ e 41,917\% de variância explicada e componente $2=1,494 \mathrm{e}$ $29,874 \%$ de variância explicada). O valor do KMO foi satisfatório $(0,623)$ e a prova de esfericidade de Bartlett confirmou correlaçóes significativas (Qui-quadrado $=$ 364,$498 ; \mathrm{df}=10 ; \mathrm{p}=0,0001$ ), porém os itens não apresentaram carga fatorial, inclusive após a solução rotada, condicente com o modelo procurado. Isto é, os cinco itens resultantes no modelo final não definiram claramente os dois fatores identificados inicialmente pela regra de Kaiser, sendo que itens identificados como açóes no ataque carregaram junto com itens identificados como situaçóes de defesa no mesmo fator. A partir desses resultados, os pesquisadores optaram por descartar esse procedimento (TCTP: OE 1 com o pé) das análises.

A TABELA 4 apresenta os valores das comunalidades e carga fatorial dos seis itens que carregaram satisfatoriamente em um dos dois fatores definidos pelo critério dos autovalores ou regra de Kaiser (componente $1=2,630$ e 43,832\% de variância explicada e componente $2=1,341$ e 22,353\% de variância explicada), para o TCTP: OE 2 executado com a máo.

TABELA 4 - Comunalidade e carga fatorial dos cinco itens definidos na solução final rotada (VARIMAX) para o TCTP:OE 2 realizado com a mão.

\begin{tabular}{llccc}
\hline & Itens selecionados & Comunalidade & \multicolumn{2}{c}{ Carga fatorial } \\
& & & Fator 1 & Fator 2 \\
\hline 1 & Movimenta-se procurando receber a bola (JSB). & 0,693 & 0,170 & 0,815 \\
7 & $\begin{array}{l}\text { Passa ao colega sem marcação e posiciona-se para receber (JCB). } \\
11\end{array} \quad \begin{array}{l}\text { Apoia aos colegas na defesa (cobertura) quando são superados pelo } \\
\text { adversário (MJSB). }\end{array}$ & 0,722 & $-0,051$ & 0,848 \\
12 & $\begin{array}{l}\text { Apoia ao colega na defesa quando o jogador com bola tem dificuldade } \\
\text { para dominá-la (MJSB). }\end{array}$ & $0,557,654$ & 0,028 \\
14 & $\begin{array}{l}\text { Pressiona ao adversário e acompanha seus deslocamentos (MJCB). } \\
16\end{array}$ & 0,645 & 0,030 \\
\hline
\end{tabular}

Na TABELA 4 observa-se que os itens 1 e 7 , que representam situaçóes de ataque sem bola e com bola, apresentam carga fatorial satisfatória no fator 2. Os itens 11, 12, 14 e 16 relacionados a situaçóes de defesa marcando ao jogador no ataque sem bola e com bola, carregam satisfatoriamente no fator 1. Nesse contexto, os pesquisadores optaram por denominar o fator 1 de defesa e o fator 2 de ataque. A porcentagem total de variância explicada pelo modelo final alcançado foi de $66,184 \%$.

$\mathrm{O}$ valor do $\mathrm{KMO}$ calculado com os cinco itens que apresentaram cargas fatoriais satisfatórias no modelo final resultante foi de 0,736 indicando que a técnica da análise fatorial pode ser utilizada para a amostra em questáo. A prova de esfericidade de Bartlett demonstrou que existem correlaçóes significativas (Qui-quadrado $=883,284 ; \mathrm{df}=15 ; \mathrm{p}=0,0001$ ) entre as variáveis e o modelo fatorial é pertinente.

A TABELA 5 apresenta os valores das comunalidades e carga fatorial dos cinco itens que carregaram satisfatoriamente em um dos dois fatores definidos pelo critério dos autovalores ou regra de Kaiser (componente $1=2,101$ e 42,013\% de variância explicada e componente $2=1,256$ e $25,118 \%$ de variância explicada), para o TCTP: OE 2 executado com o pé.

$\mathrm{Na}$ TABELA 5 observa-se que os itens 1 e 7 , que representam situaçóes de ataque sem bola e com bola, apresentam carga fatorial satisfatória no fator 2 . Os itens 11,12 e 16 relacionados a situaçóes de defesa marcando ao jogador no ataque sem bola e com bola, carregam satisfatoriamente no fator 1 . Nesse contexto, os pesquisadores optaram por denominar o fator 1 de defesa e o fator 2 de ataque. A porcentagem total de variância explicada pelo modelo final alcançado foi de $67,131 \%$.

$\mathrm{O}$ valor do $\mathrm{KMO}$ calculado com os cinco itens que apresentaram cargas fatoriais satisfatórias no modelo final resultante foi de 0,630 , indicando que a técnica da análise fatorial pode ser utilizada para a amostra em questáo. A prova de esfericidade de Bartlett demonstrou que existem correlações significativas 
(Qui-quadrado $=405,682 ; \mathrm{df}=10 ; \mathrm{p}=0,0001$ ) entre as variáveis e o modelo fatorial é pertinente.

Finalmente, a TABELA 6 apresenta a versão final do TCTP: OE após a análise fatorial (AF) exploratória, relacionando todos os itens que oportunizaram a solução ou modelo final satisfatório para o TCTP: OE 1 realizado com a mão e TCTP: $\mathrm{OE} 2$ realizado com a mão e com o pé.

TABELA 5 - Comunalidade e carga fatorial dos cinco itens definidos na solução final rotada (VARIMAX) para o TCTP:OE 2 realizado com o pé.

\begin{tabular}{llccc}
\hline & Itens selecionados & Comunalidade & \multicolumn{2}{c}{ Carga fatorial } \\
& & & Fator 1 & Fator 2 \\
\hline 1 & Movimenta-se procurando receber a bola (JSB). & 0,698 & 0,084 & 0,832 \\
7 & Passa ao colega sem marcação e posiciona-se para receber (JCB). & 0,688 & 0,076 & 0,826 \\
11 & $\begin{array}{l}\text { Apoia aos colegas na defesa (cobertura) quando são superados } \\
\text { pelo adversário (MJSB). }\end{array}$ & 0,545 & 0,728 & 0,119 \\
12 & $\begin{array}{l}\text { Apoia ao colega na defesa quando o jogador com bola } \\
\text { tem dificuldade para dominá-la (MJSB). }\end{array}$ & 0,756 & 0,868 & 0,058 \\
16 & Pressiona ao adversário levando-o para os cantos do campo de jogo (MJCB) & 0,669 & 0,816 & 0,052 \\
\hline
\end{tabular}

TABELA 6 - Versão final do TCTP:OE 1 realizado com a mão e 2 realizado com a mão e o pé, após AF exploratória.

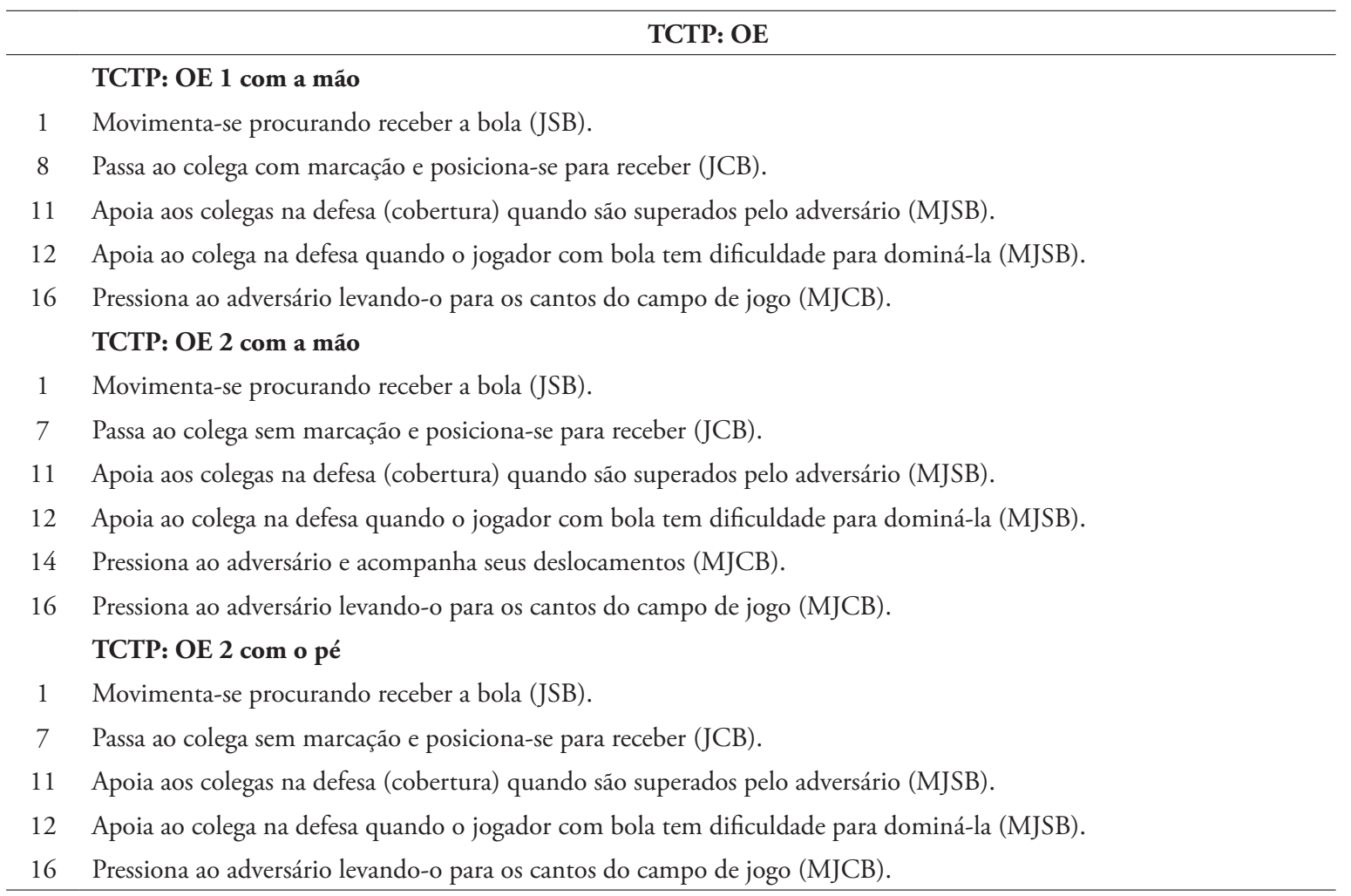

A TABELA 7 apresenta os valores do ICC para cada uma das situaçôes avaliadas, jogador no ataque sem bola (JSB), jogador no ataque com bola JCB, marcação ao jogador sem bola (MJSB) e marcação ao jogador com bola (MJCB), no TCTP: OE 1 e 2 realizados com a mão e com o pé. Pode-se afirmar que os valores do ICC calculados para o TCTP: OE foram satisfatórios (ICC $=0,4-0,74)$ e excelentes (ICC $\geq 0,75)$, de acordo com Szklo e Nieto ${ }^{31}$ determinando a confiabilidade do instrumento. 
TABELA 7 - Cálculo do ICC para o TCTP: OE 1 e 2 realizado com a mão e com o pé.

\begin{tabular}{lcc}
\hline Item e forma de realizaçáo & ICC & Valor de P \\
\hline Jogador sem bola - JSB/Mão & 0,742 & 0,000 \\
Jogador sem bola - JSB/Pé & 0,765 & 0,000 \\
Marcação ao jogador sem bola - MJSB/Mão & 0,727 & 0,000 \\
Marcação ao jogador sem bola - MJSB/Pé & 0,672 & 0,000 \\
Jogador com bola - JCB/Mão & 0,777 & 0,000 \\
Jogador com bola - JCB/Pé & 0,797 & 0,000 \\
Marcação ao jogador com bola - MJCB/Mão & 0,768 & 0,000 \\
Marcação ao jogador com bola - MJCB/Pé & 0,730 & 0,000 \\
\hline
\end{tabular}

\section{Discussão}

Observa-se na literatura que os instrumentos mais utilizados para avaliar o conhecimento tático processual de praticantes dos jogos esportivos coletivos de invasão em situação de jogo reduzido, são o denominado $\mathrm{GPAI}^{22}$, o Team Sport Assessment Procedure (TSAP) desenvolvido por GrÉHAIGNE et al. ${ }^{19}$ e o GTS ${ }^{20-21}$.

O GPAI propóe avaliar a tomada de decisão, a execução, o apoio e o ajuste em uma situação de jogo reduzido nas estruturas de $2 \times 2,3 \times 3,4 \times 4,5 \times 5$ e $6 \times 6^{22}$.

O TSAP foi proposto para avaliar o desempenho tático e técnico do aluno de educação física em situação de jogo reduzido, a partir da observação de duas grandes categorias. A primeira está relacionada com o momento em que o jogador recupera a posse de bola. A segunda refere-se aos procedimentos que o jogador deve empregar em posse de bola ${ }^{19}$.

O GTS foi proposto com a finalidade de avaliar o desempenho tático de forma quantitativa e qualitativa, através de duas situaçôes que se apresentam nos JEC, reconhecimento dos espaços e oferecer-se e orientarse. Para isso, o comportamento do avaliado é filmado para posteriormente ser avaliado por três peritos, que deverão emitir uma nota e um conceito em relação à criatividade e inteligência táticas que demonstrou o avaliado durante as situaçóes de jogo propostas ${ }^{20-21}$.

Nesse contexto o conhecimento tático processual se apresenta como uma das principais variáveis selecionadas para determinar a eficácia do processo de ensino-aprendizagem nos JEC, no âmbito da educação física escolar ou da iniciação esportiva.

O TCTP: OE surge como uma alternativa para avaliar o conhecimento tático processual na iniciação aos jogos esportivos coletivos de invasão (JECI), oportunizando, além da avaliação do jogador no ataque sem posse de bola e com posse de bola, a avaliação do jogador que atua na defesa marcando ao jogador sem posse de bola e com posse de bola.

Em relação à validade de conteúdo, pode-se afirmar que o CVC calculado para clareza da linguagem $\left(\mathrm{CVC}_{\mathrm{r}}=0,83\right)$, pertinência prática $\left(\mathrm{CVC}_{\mathrm{t}}=0,91\right) \mathrm{e}$ relevância teórica $\left(\mathrm{CVC}_{\mathrm{t}}=0,95\right)$ do TCTP: $\mathrm{OE}$ foi satisfatório. Observa-se que as ações tático-técnicas propostas representam comportamentos típicos referenciados nas modalidades esportivas coletivas de invasão (basquetebol, futsal e handebol) tomadas como base para a elaboração do TCTP: OE.

Constata-se na literatura a utilização do CVC como parâmetro adequado na investigação de evidência de validade de conteúdo em instrumentos psicométrico. No estudo de Valentini et. al. ${ }^{32}$ os valores calculados do CVC para o teste de desenvolvimento motor grosso foram de $\mathrm{CVC}_{\mathrm{t}}=0,96$ para clareza da linguagem e de $\mathrm{CVC}_{\mathrm{t}}=0,96$ para pertinência prática. No estudo de Aburachid et al. ${ }^{33}$, o processo de validade de conteúdo do teste de conhecimento tático para o tênis determinou um $\mathrm{CVC}_{\mathrm{t}}=0,89$ para clareza da linguagem e um $\mathrm{CVC}_{\mathrm{t}}=0,91$ para pertinência prática. No processo de validaçáo do teste de coordenaçáo com bola (TECOBOL) proposto por SiLvA ${ }^{34}$, o valor calculado para clareza da linguagem foi de $\mathrm{CVC}_{\mathrm{t}}=0,93$, para relevância teórica foi de $\mathrm{CVC}_{\mathrm{t}}=0,99$ e para representatividade foi de $\mathrm{CVC}_{\mathrm{t}}=0,90$.

No que se refere à validade de construto o TCTP: OE 1 realizado com a mão, o TCTP: OE 2 realizado com a máo e com o pé atingiu propriedades psicométricas satisfatórias e de acordo com o recomendado pela literatura ${ }^{25,30,35-37}$. No entanto, o TCTP: OE 1 realizado com o pé não alcançou uma solução final adequada, sendo necessário 
desconsiderar esse procedimento no protocolo desenvolvido. Observa-se que a interpretação do $\mathrm{KMO}$, do teste de esfericidade de Bartlett, dos autovalores e das cargas fatoriais são evidências de validade de construto no TCTP: OE, isto é, as variáveis empíricas ou itens propostas se agruparam adequadamente em dois fatores conforme a função de ataque ou de defesa que cada uma delas representa.

Nesse contexto, a AFE estabeleceu o modelo final com dois fatores. O fator um agrupou as ações táticotécnicas que descrevem o comportamento do jogador na defesa marcando ao atacante sem posse de bola e com posse de bola. O fator dois agrupou as açôes tático-técnicas do jogador no ataque sem posse de bola e com posse de bola. Dessa maneira, observa-se que o TCTP: OE avalia o conhecimento tático processual do praticante em situaçáo de ataque e defesa, conforme proposto inicialmente na construção do instrumento, isto é, possibilita mensurar a maneira como o praticante age em situaçáo de jogo reduzido de $3 \times 3$, selecionando o gesto técnico mais adequado no intuito de resolver os problemas que defronta durante o procedimento de avaliaçáo.

Observa-se que o TCTP: OE 2 viabiliza a avaliação do praticante com mão/pé, o que determina uma avaliação condizente com os atuais preceitos da iniciação esportiva. Isto é, o professor que utilizar o instrumento proposto terá critérios de avaliação do praticante de maneira geral, oportunizando o acesso a informaçóes que contribuam para aprimorar o processo de ensino-aprendizagem dos jogos esportivos coletivos de invasão.
Ressalta-se que o processo de iniciação esportiva nos JEC deve possibilitar no praticante a aquisição do conhecimento tático processual, por meio de atividades que apresentem elementos do jogo real, no intuito de compreender a dinâmica dos processos ofensivos e defensivos da modalidade esportiva ${ }^{16}$.

A proposta de registro e observação do conhecimento tático processual no TCTP: OE viabiliza a avaliaçáo do praticante, de acordo com critérios de referência, por exemplo, por meio da análise de percentil, além de apresentar uma forma de avaliação simples e de fácil compreensão para os avaliadores.

Considerando que o instrumento proposto foi desenvolvido para ser usado na escola, na escolinha ou no clube, uma das limitaçôes observadas é que no processo de construção do TCTP: OE não foi considerado o hóquei sobre grama, o "rugby", entre outras, pois são modalidades esportivas pouco praticadas na escola no Brasil. Em relação ao futebol, sugere-se a realização de outros estudos para se considerar a opção da confiabilidade do procedimento avaliativo para esta modalidade esportiva, em que o equipamento e espaço específico, bola e campo sejam utilizados na execução do teste.

Após esta fase do estudo, inicia-se o processo de normatização do TCTP: OE 2 com a mão e com o pé, por apresentar propriedades psicométricas satisfatórias, que se apoiam nos índices de evidência de validade de conteúdo, validade de construto e de confiabilidade.

Finalmente, em relação à confiabilidade do instrumento, observa-se que o TCTP: OE apresentou valores satisfatórios e excelentes de acordo com o recomendado pela literatura ${ }^{31,38-39}$.

\begin{abstract}
Validity evidence of procedural tactical knowledge test for sports guidance

This study aimed to investigate the evidence validate content, construct and test the reliability of procedural tactical knowledge for sporting orientation (TCTP: OE) of children and youth in sports games collective invasion (basketball, futsal and handball). In the process of content validity participated as judges 11 technicians, and 3 basketball, 4-five side indoor football, and 4 handball. In empirical procedures to sample comprised a total of 570 participants. The average age of study participants was $10.32 \pm 1.45$ years. Content validity was determined by calculating the coefficient of content validity (CVC). We used exploratory factor analysis (EFA) for construct validity. The method used was principal components with Varimax orthogonal rotation and Kaiser normalization. The reliability of the TCTP: EO was established through the test-retest method on different days. The technique used was the intraclass correlation (ICC). Regarding content validity of the CVC calculated for clarity of language $\left(\mathrm{CVC}_{t}=0.83\right)$, practical relevance $\left(C V C_{t}=0.91\right)$ and theoretical relevance $\left(C V C_{t}=0.95\right)$ was satisfactory. Factor analysis confirmed the structure of the final model with two factors, called attack and defense, explaining in all cases over 66\% of the variance. Regarding the reliability of the instrument TCTP: OE showed satisfactory
\end{abstract}


values and excellent (ICC $\geq 0.4$ ). We conclude that the TCTP: OE enables the evaluation of the player is with hand / foot, which determines an assessment consistent with current precepts of sport initiation.

KEY WoRdS: Performance tactical; Decision making; Tactical behavior; Validation.

\section{Referências}

1. Sonnenschein I. Wahrnehmung und taktisches Handeln im Sport. Berlin: BPS; 1987. (Betrifft Psychologie \& Sport Sonderband 10).

2. Tenenbaum G, Bar-Eli M. Decision making in sport: a cognitive perspective. In: Singer RN, Murphey M, Tennant KL, editores. Handbook of research on sport psychology. New York: MacMillan; 1993. p.171-92.

3. Eysenck M, Keane M. Psicologia cognitiva: um manual introdutório. Porto Alegre: Artes Médicas; 1994.

4. Hossner HJ. Module der motorik. Schorndorf: Hofmann; 1995.

5. Marina IA Teoria da inteligência criadora. Lisboa: Anagrana; 1995.

6. Hossner HJ. Principles to know on nodals points. Coach: FIVB Mag Volleyball Coaches. 2000;1:6-11.

7. Roth K, Raab M, Greco PJ. Das modell der inzidentellen inkubation: eine uberprufung der kreativitatsentwicklung brasilianischer und deutsher sporstspieler. Heidelberg: ISSW; 2000. (Unveroffentlichter Projektbericht).

8. Sternberg RJ. Psicologia cognitiva. Porto Alegre: Artmed; 2000.

9. Abernethy AB. Sports as expertise, psychology. In: Smelser NJ, Baltes PB, editores. International encyclopedia of the social and behavioral sciences. Oxford: Pergamon; 2001. p.14935-8.

10. Abernethy AB. Attention. In: Singer N, Hausenblas HA, Janelle C, editors. Handbook of research on sport psychology. New York: John Wiley; 2001. p.53-85.

11. Anderson JR. Psicologia cognitiva e suas implicaçóes experimentais. Rio de Janeiro: LTC; 2004.

12. Greco PJ, Roth K, Schörer J. Ensino-aprendizagem-treinamento da criatividade tática nos jogos esportivos coletivos. In: Garcia E, Lemos K, editores. Temas atuais IX Educação Física e Esportes. Belo Horizonte: Saúde; 2004. p.52-63.

13. Anderson JR. Aprendizagem e memória: uma abordagem integrada. Rio de Janeiro: LTC; 2005.

14. Tenenbaum G, Lidor R. Research on decision-making and the use of cognitive strategies in sport settings. In: Hackfort D, Duda J, Lidor R, editors. Handbook of research in applied sport and exercise psychology: International perspectives. Morgantown: Fitness Information Tecnology; 2005. p.75-91.

15. Greco PJ. Conhecimento tático-técnico: eixo pendular da açáo tática (criativa) nos jogos esportivos coletivos. Rev Bras Educ Fis Esporte. 2006;20:210-2.

16. Greco, PJ, Benda R N, organizadores. Iniciação esportiva universal: da aprendizagem motora ao treinamento técnico. Belo Horizonte: UFMG; 1998.

17. Costa I, Garganta J, Greco PJ, Mesquita I, Maia J. Sistema de avaliação tática no futebol. Motricidade. 2011;1:69-84.

18. French KE, Thomas J. The relation of knowledge development to children's basketball performance. J Sport Psychol. 1987;9:15-32.

19. Gréhaigne JF, Godbout P, Bouthier D. Performance assessment in team sports. J Teach Phys Educ. 1997:16:500-516.

20. Memmert D, Roth K. Diagnostics of individual tactical performance in sports games. Spektrum Sportwissenschaft. 2003; 15:44-70.

21. Memmert D. Developing creative thinking in a gifted sport enrichment program and the crucial role of attention processes. High Ability Stud. 2006;17:101-15.

22. Oslin JL, Mitchell SA, Griffin LL. The game performance assessment instrument (GPAI): development and preliminary validation. J Teach Phys Educ. 1998;17:231-43.

23. Urbina S. Fundamentos da testagem psicológica. Porto Alegre: Artmed; 2007.

24. Messick S. Foundations of validity: meaning and consequences in psychological assessment. Eur J Psychol Assess. 1994;10:1-9.

25. Pasquali L. Testes referentes a construto: teoria e modelo de construção. In: Pasquali L, organizador. Instrumentação psicológica: fundamentos e práticas. Porto Alegre: Artmed; 2010. p.165-98.

26. McPherson SL, Thomas JR. Relation of knowledge and performance in boys' tennis: age and expertise. J Exp Child Psychol. 1989;48:190-211. 
27. Turner A, Martinek T. Teaching for understanding: a model for improving decision making during game play. Quest. 1995;44:44-63.

28. Hernández-Nieto RA. Contributions to statistical analysis. Mérida: Universidad de Los Andes; 2002.

29. Tabachnick B, Fidell L. Using multivariate statistics. New York: Harper \& Row; 1989.

30. Balbinotti MAA. Para se avaliar o que se espera: reflexóes acerca da validade dos testes psicológicos. Aletheia. 2005;21:43-52.

31. Szklo M, Nieto FJ. Epidemiology: beyond the basics. Gaithersburg: ASPEN; 2000.

32. Valentini NC, Barbosa MLL, Cini GV, Pick RK, Spessato BC, Balbinotti MAA. Teste de desenvolvimento motor grosso: validade e consistência interna para uma população gaúcha. Rev Bras Cineantropom Desempenho Hum. 2008;10:399-404.

33. Aburachid LMC, Morales JCP, Greco PJ. Test validation process of tactical knowledge in tennis: the influence of practice time and competitive experience. Int J Sports Science. 2013;3:13-22.

34. Silva S. Manual do teste de coordenação com bola: tecobol. Rev Port Cienc Desporto. 2011;11:92.

35. Angers M. Initiation pratique à la méthodo logie des sciences humaines. Montreal: Les Éditions de la Cheneliére; 1992.

36. Asci FH, Asci A, Zorba E. Cross-cultural validity and reliability of physical self-perception profile. Int J Sport Psychol. 1999;3:399-406.

37. Lopes HEG. Abrindo a caixa preta: consideraçóes sobre a utilização da análise fatorial confirmatória nas pesquisas em administração. Economia Gestão. 2005;5:19-34.

38. Hopkins WG. Measures of reliability in sport medicine and science. Sports Med. 2000;30:1-15.

39. Usubiaga O, Castellano J, Blanco A. Precisión de generalización en un diseño multifaceta configurado para la observación de la pelota a mano por parejas. Metodol Cienc Comport. 2004;N. espec:595-602.

\section{Agradecimentos}

Projeto com apoio do CNPq bolsa produtividade. Processo n. 308962. 2008-7 PQ. 10/2008.

Gostaríamos de agradecer ao Grupo de Estudos das Capacidades de Rendimento dos Esportes Coletivos (GECREC) coordenado pela professora Dra. Siomara Silva do Centro Esportivo Universitário da Universidade Federal de Ouro Preto.

Este estudo contou com a valiosa colaboração das professoras Fabiola Araujo e Camila Texeira, dos professores Ciro Guerra Torres, Henrique de Oliveira Castro e Ivan Cavalli, bem como dos acadêmicos Cristovão Loyola Pinto Guimaraes, Guilherme Loyola Pinto Guimaraes, Nathalia Lelis Torres e Samantha Rodrigues, membros pesquisadores do Centro de Estudos de Cognição e Ação do Centro de Excelência Esportiva da Escola de Educação Física, Fisioterapia e Terapia Ocupacional da UFMG.

\begin{tabular}{r|r} 
ENDEREço & \\
Pablo Juan Greco & Recebido para publicação: 07/04/2013 \\
Escola de Educação Física, Fisioterapia e Terapia Ocupacional & $\begin{array}{l}\text { Universidade Federal de Minas Gerais } \\
\text { Revisado: 14/04/2014 } \\
\text { Av. Pres. Antônio Carlos, 6627 - Campus Pampulha } \\
\text { Aceito: 12/12/2014 } \\
\text { e-mail: grecopj@ufmg.br }\end{array}$ \\
\end{tabular}

